\title{
Intelligence indices in people with a high/low risk for developing Huntington's disease
}

Gerly M de Boo, Aad Tibben, Jan B K Lanser, Aag Jennekens-Schinkel, Jo Hermans, Maria Vegter-van der Vlis, Raymund A C Roos

\section{Department of}

Neurology, Leiden

University Hospital,

PO Box 9600, 2300 RC

Leiden, The

Netherlands

G M de Boo

J B K Lanser

A Jennekens-Schinkel ${ }^{\star}$

R A C Roos

Department of

Medical Psychology

and Psychotherapy,

Erasmus University

and University

Hospital Dijkzigt,

Rotterdam, The

Netherlands

$\mathrm{G} M$ de Boo

A Tibben

Department of Clinical

Genetics, Erasmus

University and

University Hospital

Dijkzigt, Rotterdam,

The Netherlands

A Tibben

Department of

Medical Statistics,

Leiden University,

Leiden, The

Netherlands

J Hermans

Department of Clinical

Genetics, Leiden

University Hospital,

Leiden, The

Netherlands

$M$ Vegter-van der Vlis

Correspondence to:

Dr de Boo.

^Present address: Wilhelmina Children's Hospital, Utrecht University Hospital, The Netherlands.

Received 3 September 1996 Revised version accepted for publication 7 March 1997

\begin{abstract}
Intelligence in 20 presymptomatic subjects with an increased risk $(>95 \%)$ for carrying the gene for Huntington's disease (HD) was studied in a prospective, casecontrol, single blind study. No significant differences between the groups were detected for intelligence indices and subtest scores (Wechsler Adult Intelligence Scale). The high level of the performance IQ and the significant discrepancy between performance IQ and verbal IQ found in both the high risk and the low risk groups contrasted with our expectations based on anamnestic information, general clinical opinion, and the results of previously conducted studies. We propose that psychosocial circumstances could explain the test results and discuss the consequences of our findings for clinical genetics practice.
\end{abstract}

(F Med Genet 1997;34:564-568)

Keywords: Huntington's disease; neuropsychology; intelligence; early symptoms

Huntington's disease (HD) is an autosomal dominantly inherited, neurodegenerative disorder characterised by involuntary movements, changes in behaviour and personality, and cognitive impairment. Because the mean age of onset is 40 years (range 2 to 80 years), ${ }^{1}$ people at risk will always remain at risk for this disease.

Linkage and mutation analyses have offered options for predictive testing for HD. ${ }^{2}$ Previous studies of expectations of at risk subjects have suggested that psychological effects of testing might include severe psychosocial problems, such as increased awareness of early symptoms, depression, and suicidal behaviour in identified gene carriers. ${ }^{3-6}$ Generally, however, follow up studies have indicated that tested subjects found relief from their previous psychological distress and that they benefited psychologically from testing. ${ }^{7-10}$ Most carriers seemed to cope well, although this was based largely on strong psychological defence and dependent on satisfactory relationships. An unresolved question is how the foreknowledge of becoming affected will influence carriers as they approach the impending onset of HD. There is a risk of underestimation of worries and anxiety given the current experience with identified carriers who reacted with depression and suicidal behaviour after confirmation of the clinical diagnosis. $^{7}$
DNA testing has also found its way to departments of neurology and will be increasingly used for confirmation of the (differential) diagnosis in patients suspected of having the disease. Before the advent of DNA testing programmes, the diagnosis was based on involuntary, choreic movements and a positive family history. The eventual clinical diagnosis of HD is obviously psychologically devastating to the partner and his/her offspring, who have seen the patient's parent, sib, or another close relative become progressively disabled. The diagnosis was often made in the later stages of the disease, when personality or cognitive changes or both were already prominent. Before the diagnosis was made, families were often left in the dark and adequate support could not be offered because of lack of recognition of symptoms or knowledge of the disease. Moreover, misdiagnosis of $\mathrm{HD}$ as depression, for example, sometimes occurs in the early stages of the disease, which has led to unsuccessful psychotherapy. Therefore, an early diagnosis of the disease could be relevant for appropriate support and for preparing a patient and his family more adequately for the future deterioration.

The actual sequence of appearance of the three major symptoms (movement disorders, personality changes, and cognitive changes) is not known. Manifest choreic movements may be preceded by early affective or cognitive changes. ${ }^{11-13}$ In addition, little is known about the early distinguishing features of cognitive decline since neurological and neuropsychological studies are generally conducted after motor symptoms have already become manifest. An important method for increasing insight into the early phases of the onset of the disease is to follow up identified carriers with non-carriers as a control group. After a predictive genetic diagnosis is obtained in carriers, early cognitive symptoms can be studied over an extended period. Our primary interest concerns indices of general intelligence as presented by the full scale IQ, verbal IQ, and performance IQ (Wechsler Adult Intelligence Scale). These indices are commonly used to assess overall cognitive decline, and they are also popular among clinicians outside the field of psychology. Lyle and Gottesman ${ }^{12}{ }^{13}$ studied cognition of presymptomatic subjects at risk for $\mathrm{HD}$ and reported the results 15 to 20 years later for the group which had developed symptoms and for the group which remained symptom free. The IQs, especially the PIQ, of those who had developed the disease were 
significantly lower than the IQs of those who stayed free of symptoms. They suggest intelligence indices to be sensitive indicators for early cognitive decline. Therefore intelligence tests could be useful to clinicians in diagnosing the start of cognitive deterioration in HD.

In this article we address the question whether subjects at high risk (HD+) can be distinguished from those at low risk (HD-) with regard to intelligence indices. Given the characteristics and the insidious course of the disease, our hypothesis was that the HD+ group would perform significantly less well than the HD- group in the Wechsler Adult Intelligence Scale, especially in the performance tasks. Performance tasks are considered more sensitive than verbal tasks to disturbances of the integrity of the central nervous system.

\section{Participants and methods \\ TESTING PROCEDURE}

The presymptomatic test for $\mathrm{HD}$, using DNA linkage analysis, has been available at the Clinical Genetics Centre in Leiden since October $1987 .{ }^{14}$ No official announcement was made by the Genetics Centre as a restrained policy was applied. Information about the availability of the test was given by either the general practitioner, neurologist, clinical genetics service, relatives, or patient organisation. The counselling protocol included at least two sessions of pretest counselling, and was undertaken along the lines of a structured protocol following the international guidelines. The testing protocol has been previously described. ${ }^{14}$ Inclusion criteria for the testing programme included: age 18 years or older, absence of major mental illness or the intention to commit suicide after an unfavourable result, and the ability to give informed consent. Neurological and neuropsychological examinations were not performed as a standard part of the testing protocol. If applicants had reason to believe that they were perhaps affected, they were referred to the neurologist of the team (RACR). If the genetic counsellor or psychologist suspected an applicant to be affected, it was thoroughly discussed whether the applicant was preoccupied with early signs of the disease and whether he/she wished to learn about confirmation of the disease when identified as a carrier of the HD gene. When applicants denied early symptoms or avoided discussing them, this was considered and appreciated as warding off behaviour. Test results were disclosed about three months after the intake session.

\section{PARTICIPANTS}

Between 1 April 1989 and 31 March 1991, 114 subjects at $50 \%$ risk entered the presymptomatic testing programme at the Clinical Genetics Centre, Leiden. Seventy-three could be given results and participated in a psychological follow up study. Twenty-nine persons with an increased risk (96-98\%) and 44 persons with a decreased risk (2-4\%) were diagnosed by linkage analysis. All were tested at their own request and gave informed consent to participate in the testing procedure and fol-
Table 1 Demographic, social, and medical characteristics of participants

\begin{tabular}{lll}
\hline & $H D+(n=20)$ & $H D-(n=26)$ \\
\hline Mean (SD) age in years & $34.4(10.1)$ & $37.1(9.8)$ \\
Sex: female/male & $13 / 7$ & $17 / 9$ \\
Level of education & 3 & 2 \\
$\quad$ Primary school & 4 & 9 \\
$\quad 10$ years education & 10 & 9 \\
11 years education & 3 & 6 \\
$\quad 12$ years education & 9 & 0 \\
Repeating classes & 3 & 4 \\
History of brain trauma & & \\
Hereditary illness other than & 0 & 1 \\
$\quad$ HD & & \\
Use of medicine & 1 & 0 \\
$\quad$ Neuroleptics & 2 & 3 \\
$\quad$ Other & & \\
Alcohol & 6 & 9 \\
$\quad$ None & 12 & 12 \\
$\quad$ 5-15 units/week & 1 & 3 \\
$\quad$ 15 units/week & 1 & 2 \\
Complaints about mental & & \\
$\quad$ function & & 3 \\
$\quad$ Memory & 2 & 2 \\
$\quad$ Concentration & 3 & \\
\hline
\end{tabular}

low up research programme. This programme was approved by the Medical Ethics Committee of our hospital. In the present study, started in 1993, 46 subjects ( 20 at high risk and 26 at low risk) participated. The group characteristics of the participants are given in table 1 . Twenty-seven subjects were lost for the following reasons: six persons had become symptomatic and were therefore not approached for cooperation, two persons moved abroad, four moved without leaving an address, three had experienced severe problems with coping with the test result and did not wish to cooperate for fear of reactivation of the burden, two reported that HD was no longer an issue for them and they felt no need for follow up contacts, two had physical problems (bowel cancer, severe cardiac illness), and two participants refused the neuropsychological part of the follow up study. Two out of three non-carriers who had postponed the follow up appointment several times were involved in caring for the affected parent or sibs. Three subjects responded to the invitation but broke off the testing procedure early. The group that was lost to follow up did not differ significantly from the present study group on either age, DNA test disclosure (high/low risk), time lag, gender or marital status, or the scores on psychological measures at baseline and the six month follow up..$^{15}$

\section{METHODS}

Demographic data and medical and social information were collected in an interview. Intelligence (full scale IQ, verbal IQ, and performance IQ) was assessed with the Wechsler Adult Intelligence Scale (Dutch translation) (WAIS). ${ }^{16}$ Firstly, demographic variables, intelligence indices, and subtest scores were studied in both groups. Secondly, on an individual level, we compared the VIQ and PIQ.

The data were analysed using the Statistical Package for Social Sciences (chi-square test for association, $t$ test for independent samples, $t$ test for paired samples); $p$ levels of 0.05 or less are reported as significant. 
Table 2 WAIS scores in HD- and HD+ groups

\begin{tabular}{llll}
\hline & $H D-(n=26)$ & $H D+(n=20)$ & $t$ test \\
\hline Full scale IQ & $110(10)$ & $111(13)$ & 0.87 \\
Verbal IQ & $105(11)$ & $106(15)$ & 0.85 \\
Performance IQ & $115(9)$ & $115(13)$ & 0.92 \\
Information & $6.0(1.2)$ & $5.9(1.8)$ & 0.73 \\
Comprehension & $5.7(2.2)$ & $6.0(2.4)$ & 0.66 \\
Arithmetic & $5.6(1.9)$ & $5.5(1.8)$ & 0.84 \\
Similarities & $7.2(1.9)$ & $6.9(2.3)$ & 0.54 \\
Digit span & $4.9(1.5)$ & $5.8(1.8)$ & 0.08 \\
Vocabulary & $5.4(1.8)$ & $5.7(2.5)$ & 0.72 \\
Digit/symbol & $6.9(1.9)$ & $6.0(1.4)$ & 0.07 \\
Picture completion & $6.5(1.5)$ & $7.1(2.2)$ & 0.25 \\
Block design & $6.7(1.7)$ & $6.7(1.6)$ & 0.99 \\
Picture arrangement & $6.6(1.8)$ & $7.0(1.9)$ & 0.45 \\
Object assembly & $6.7(1.3)$ & $6.5(1.8)$ & 0.68 \\
\hline
\end{tabular}

\section{Results}

Demographic, medical, and social variables were equally distributed in the $\mathrm{HD}+$ and the HD- groups as no significant differences were found (table 1). We found no indications that asymptomatic $\mathrm{HD}+$ subjects differ from $\mathrm{HD}$ subjects, as the intelligence variables full scale IQ (FSIQ), verbal IQ (VIQ), and performance IQ (PIQ) and the subtests showed no differences between HD+ and HD- (table 2). However, within each group the PIQ was significantly higher than the VIQ ( $p<0.001$ for HD-, $\mathrm{p}<0.03$ for $\mathrm{HD}+$ ) (table 3, fig 1 ).

\section{Discussion}

It was found that the intelligence indices of identified HD+ did not differ from identified HD-, which is in agreement with other studies. ${ }^{19-23}$ Also, in the studies which claim to have found signs of cognitive deterioration in HD+ participants as opposed to HDparticipants, ${ }^{22-24}$ these signs did not show in the intelligence indices. IQ indices are commonly treated as global indicators of general adaptive abilities. Therefore, it is of importance to clinicians and counsellors to be aware that in none of the studies in the presymptomatic stages was deterioration of intelligence found. However, global indices of intellectual function might not be useful in distinguishing features of early cognitive decline. In this study a discrepancy in the intelligence parameters was found, as the PIQ exceeded the VIQ in both groups with statistical significance. Performance tasks typically require learning and problem solving in new situations in which stored knowledge and previously acquired skills are of little use. This type of intelligence is considered most dependent on continued integrity of the central nervous system and is therefore sensitive to brain damage. Performance tasks are reported to be specifically vulnerable in HD. ${ }^{13}{ }^{25}$ Our expectation that the first signs of intellectual deterioration would be reflected in a decline in performance tasks was not confirmed, possibly because there was as yet no deterioration. Contrary to our expectations, we found that the PIQ was higher than expected taking educational background into account. Therefore, decline in performance tasks in this study group would go unnoticed if these premorbid baseline data were lacking (as they usually are in clinical practice). Another point of interest is the fact that the PIQ was significantly higher than the VIQ. A low VIQ and a high PIQ can result from language dysfunction. The assumption of language dysfunction is, however, not very likely since language disturbances are not a feature of HD. ${ }^{26}$

As the pattern of the intelligence indices is similar for the HD+ group as well as for the HD- group, we can reject a HD linked genetic explanation and consider a psychosocial hypothesis to explain the findings. The social environment of our subjects may have discouraged academic training. Presumably growing up in family affected with HD, under threat of this serious disease, has led to educational underachievement and perhaps a lack of ambition. Social and educational variables are known to have an important influence on intelligence indices, especially on VIQ. However, the discrepancy between the intelligence indices could be a chance finding as it has not been found in other studies. The psychosocial hypothesis needs to be confirmed by further study with a control group from a normal population, matched for socioeconomic background.

Giordani et $a l^{20}$ also proposed psychosocial variables of influence on the test results of $\mathrm{HD}+$ and HD- subjects. They found no differences between carriers and non-carriers and both groups performed less well than normal controls. However, their normal controls are likely to come from an intellectual community of students which is, in view of the psychosocial hypothesis, a mismatched control group. In fact, any study addressing cognition of HD patients by a comparison with either normal controls or other patient groups fails to take the burdened history of HD patients into account. As predictive DNA testing becomes available for more neurodegenerative disorders, psychosocial group characteristics can be studied at a baseline level. This is an essential methodological improvement to current research designs in which premorbid data are generally lacking. Deviations from norms and from control data, which were previously interpreted as sequelae of brain pathology, might prove to result from influences indirectly related to specific diseases. The psychosocial hypothesis could be of interest to professionals who are involved in counselling subjects at risk and who give support to them and their families in need of help. Our study suggests that HD in the family may lead to a lack of encouragement for academic training and ambition. This could be an important issue in counselling the possible effects of an unfavourable test result on (future) children and personal functioning. A further consequence of the psychosocial hypothesis would be the need for special attention in schools for children from families burdened with HD.

A limitation of this study was that the neurological examination in the presymptomatic testing programme was discontinued in the first phase of the programme in 1988. Test candidates generally did not want to be informed about early signs of the disease but about the possibility of developing the disease in the future. Such an attitude in both the applicant and the partner, which reflects 
Table 3 Wechsler adult intelligence scale

\begin{tabular}{lllll}
\hline & & $H D+(n=20)$ & $H D-(n=26)$ & \\
\hline Verbal IQ & Mean (SD) & $105.6(15.4)$ & $104.8(11.4)$ & NS \\
Performance IQ & Mean (SD) & $114.7(13.3)$ & $115.0(9.1)$ & NS \\
Paired comparison & Mean (SD) & $9.1(17.4)$ & $10.2(11.5)$ & \\
VIQ-PIQ & & $\mathrm{p}<0.03$ & $\mathrm{p}<0.001$ & \\
\hline
\end{tabular}

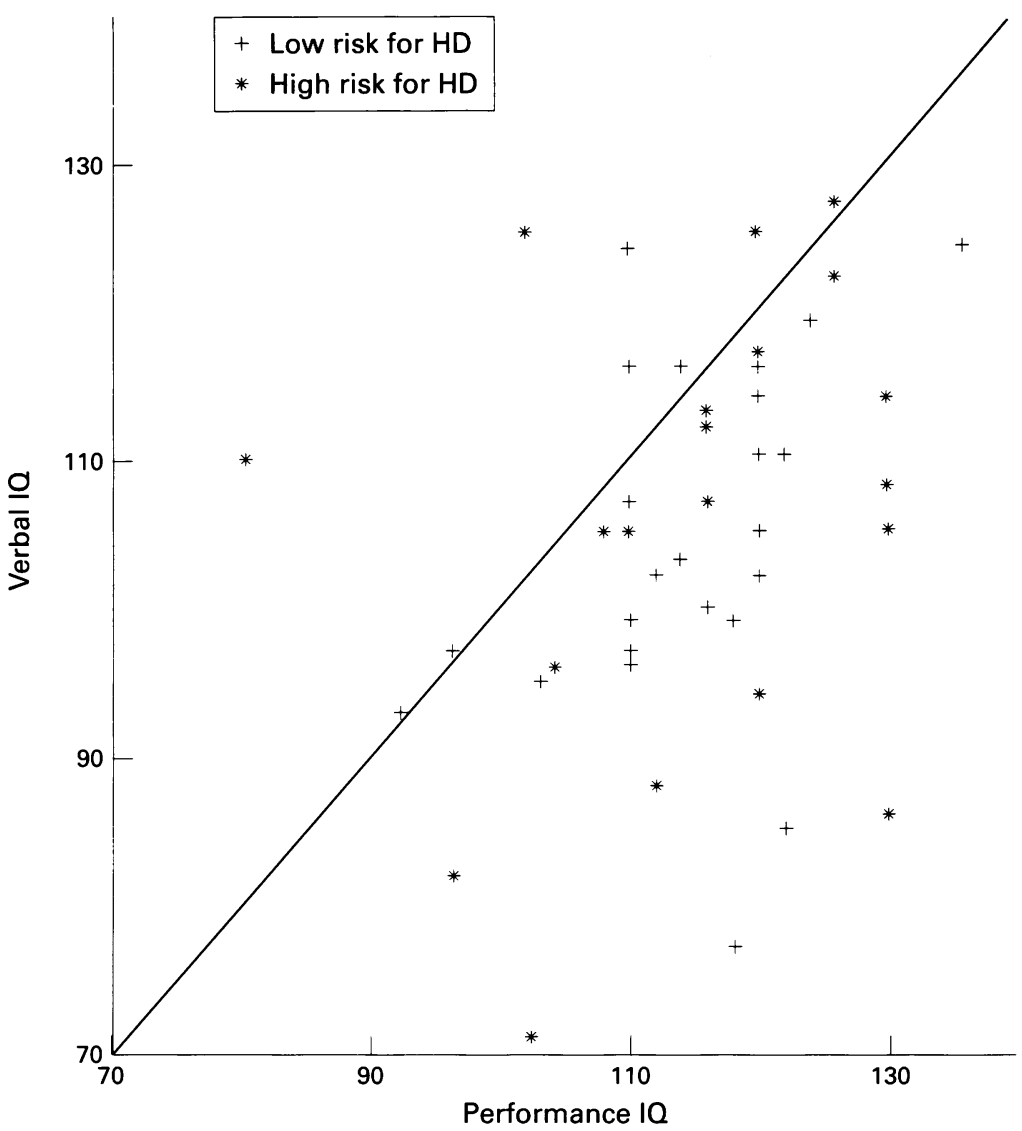

Figure 1 VIQ and PIQ (WAIS) for 20 subjects at high risk and 26 subjects at low risk for $H D$.

denial-avoidance behaviour, can be considered as the next step in adjusting to the impending burden. In the next analysis, the influence of early signs will be studied using audiovisual recordings of participants. Another limitation was that the study group was a small self-selected sample, and that a substantial group was lost to follow up (30\%). Furthermore, the DNA test was performed by linkage analysis with $96-98 \%$ reliable test results. Finally, to gain more insight into early symptoms and their impact on the subject, the disease process needs to be studied in longitudinal design.

Predictive testing for HD has been undertaken in the context of research protocols, with the inclusion of follow up studies on the psychosocial effects of receiving test results. The findings have essentially contributed to improvement in the counselling and support of test candidates. Studies on the course of this disease are now under way. It could be argued, however, that performing neuropsychological and neurological follow up for purposes of research and not for the medical evaluation of predictive testing programmes may not be acceptable given the probable burden for carriers. Obviously, the relevance of research assessments for the evaluation of predictive testing should be clarified. The eventual contribution to the improvement of the clinical service must be convincing. If these requirements are met, subjects should be encouraged to participate in research assessments, and to adhere to the provisions of a research protocol. This may be an appropriate expectation by those offering presymptomatic testing for HD or other late onset inherited disorders. It must be noted that test candidates are highly motivated to participate in these follow up studies and regard participation as professional support. ${ }^{57}$ Participants also make use of the follow up contacts to keep up to date regarding research developments.

Another issue in the present study concerns giving information about the results of research. The policy was adopted not to inform participants about their personal results because these have no diagnostic value or therapeutic consequences at this stage. However, current legislation in The Netherlands requires that study participants (over 12 years of age), at their request, should be informed of results of medical research. Test results can only be withheld if the prognostic knowledge is considered to harm the patient (the therapeutic exception). In the current study, authorised by the Hospital Medical Ethics Committee, it was agreed that participants were referred to the Department of Neurology for further counselling and neurological and neuropsychological assessment if they expressed an interest. The potential problems related to the delivery of test results at this stage can then be profoundly discussed and adequately dealt with.

More insight into early changes in cognitive functioning could be valuable for clinical genetics practice with regard to appropriate counselling and guidance in the long term. Current testing programmes allow the provision to conduct careful long term follow up studies. Patients and their families can eventually benefit from the results of these studies.

This study was supported by the Prinses Beatrix Fonds grant 92-3478.

1 Roos RAC, Vegter-van der Vlis M, Hermans J, et al. Age at onset in Huntington's disease: effect of line of inheritance and patient's sex. $\mathcal{F}$ Med Genet 1991;28:515-19.

2 Gusella JF, Wexler NS, Conneally PM, et al. A polymorphic DNA marker genetically linked to Huntington's disease. Nature 1983;306:234-9.

3 Kessler S, Field T, Worth L, Mosbarger H. Attitudes of perKessler S, Field T, Worth L, Mosbarger H. Attitudes of per-
sons at risk for Huntington disease toward predictive testsons at risk for Huntington disease to
ing. Am $\mathcal{F}$ Med Genet 1987;26:259-70.

4 Mastromauro C, Myers RH, Berkman B. Attitudes toward presymptomatic testing in Huntington disease. $\mathrm{Am} \mathcal{F} \mathrm{Med}$ Genet 1987;26:271-82.

5 Meissen GJ, Berchek RL. Intended use of predictive testing by those at risk for Huntington disease. Am $\mathcal{F}$ Med Gene 1987;26:283-93.

6 Evers-Kiebooms G, Cassiman J, van den Berghe $\mathrm{H}$. Attitudes towards predictive testing in Huntington's disease: a recent survey in Belgium. $₹$ Med Genet 1987;24 275-9.

7 Tibben A, Timman RT, Bannink EC, Duivenvoorden HJ. 3-year follow-up after presymptomatic testing for Huntington disease in tested individuals and partners. Health Psychol (in press).

8 Tibben A, Duivenvoorden HJ, Niermeijer MF, Vegter-vd Vlis M, Roos RAC, Verhage F. Psychological effects of presymptomatic DNA testing for Huntington's disease in presymptomatic DNA testing for Huntington's disease
the Dutch program. Psychosom Med 1994;56:526-32.

9 Wiggins S, Whyte P, Huggins M, et al. The psychological consequences of predictive testing for Huntington's consequences of predictive testing for Huntington's
disease. Canadian Collaborative Study of Predictive disease. Canadian Collaborative Study
Testing. N Engl f Med 1992;327:1401-5. 
10 Codori AM, Brandt JA. Psychological costs and benefits of predictive testing for Huntington's disease. Am 7 Med Genet 1994;54:174-84.

11 Cain ED, Shoulson I. Psychiatric syndromes in Huntington's disease. Am $\mathcal{F}$ Psychol 1983;140:728-34.

12 Lyle OE, Gottesman II Premorbid psychometric indicators of the gene for Huntington's disease. $\mathcal{f}$ Consult Clin Psychol of the gene for Huntington's disease. F Consult Clin Psychol

13 Lyle OE, Gottesman II. Subtle cognitive deficits as 15- to 20-year precursors of Huntington's disease. Adv Neurol 1979;23:227-38.

14 Skraastad MI, Verwest A, Bakker E, et al. Presymptomatic, prenatal, and exclusion testing for Huntington disease using seven closely linked DNA markers. Am $\mathcal{F}$ Med Genet 1991;39:217-22.

15 Tibben A, Frets PG, van der Kamp JJP, et al. Attitudes and appreciation, 6 months after presymptomatic DNA-testing Genet 1993;48:103-111.

16 Stinissen J, Willems PJ, Coetsier P, Hulsman WLL. WAIS Dutch adaptation Wechsler Adult Intelligence Scale. Lisse, The Dutch adaptation Wechsler Adult Intelligence
Netherlands: Swets \& Zeitlinger, 1979.

17 de Zeeuw J. Algemene Psychodiagnostiek I. Lisse, The Netherlands: Swets \& Zeitlinger, 1981.

18 Luteijn F, van der Ploeg FAE. Groninger Intelligentie Test. Lisse, The Netherlands: Swets \& Zeitlinger, 1982.
19 Strauss ME, Brandt J. Are there neuropsychologic manifestations of the gene for Huntington's disease in asymptomatic, at-risk individuals? Arch Neurol 1990;7:905-8.

20 Giordani B, Berent S, Boivin MJ, et al. Longitudinal neuropsychological and genetic linkage analysis of persons at risk for Huntington's disease. Arch Neurol 1995;52:5964 .

21 Blackmore L, Simpson SA, Crawford JR. Cognitive performance in UK sample of presymptomatic people performance in UK sample of presymptomatic people carrying the gene

22 Jason GW, Pajurkova EM, Suchowersky O, et al. Presymptomatic neuropsychological impairment in Huntington's disease. Arch Neurol 1988;45:769-73.

23 Diamond R, White RF, Myers RH, et al. Evidence of presymptomatic cognitive decline in Huntington's disease. $\mathfrak{f}$ Clin Exp Neuropsychol 1992;14:961-75.

24 Rosenberg NK, Sørensen SA, Christensen A. Neuropsychological characteristics of Huntington's disease carriers: double blind study. F Med Genet 1995;32:600-4.

25 Mohr E, Brouwers P, Claus JJ, Mann UM, Fedio P, Chase TN. Visuospatial cognition in Huntington's disease. Movement Disord 1991;2:127-32.

26 Podoll $K$, Caspary $P$, Lange HW, Noth J Language funct $K$, Caspary $P$, Lange $H W$, Noth J. Language Kain 1988;111:1475503. 